\title{
El movimiento del movimiento en Lumako: Pensándose como mapuche desde lo mapuche ${ }^{1}$
}

The movement in the Lumako movement: thinking as mapuche from the mapuche

Tiтo TRICOT

Sociólogo, Doctor en Sociologia, Universidad Alberto Hurtado, Chile; Magister en Politica Latinoamericana, Universidad de Essex, Inglaterra; profesor, Universidad Viña del Mar, Chile; director del Centro de Estudios de América Latina y el Caribe - CEALC, Chile.

Resumen

El objetivo del presente texto es reflexionar acerca del Movimiento Mapuche Autonomista y, particularmente, sobre el giro movimental que parece haberse verificado en Lumako ${ }^{2}$ en la década del noventa. Más especificamente, analizaremos el concepto de mapuchización de los marcos interpretativos como un elemento central en el movimiento del movimiento que apuntaba a pensarse como mapuche desde lo mapuche

Palabras clave. Movimiento Mapuche Autonomista, Lumako, Marcos interpretativos, Giro movimental.

Abstract

The aim of the present article is to reflect upon the Autonomist Mapuche Movement and, particularly, about the movemental turning point that seems to have taken place in Lumako in the 90s. Most specifically, we will analyze the concept of mapuchization of interpretative frames as central element in the movement of the movement that pointed towards thinking as a Mapuch from the Mapuche

Key Words. Autonomist Mapuche Movement, Lumako, Interpretative Frames, Movemental Turning point.

Introducción

La teluridad de los movimientos sociales dependerá, uno podría argumentar, de manera importante de las placas tectónicas de la conciencia de sus miembros, tanto en su calidad de individuos como en su condición de colectivo. Es el desplazamiento de dichas placas lo que generará el movimiento del movimiento, y este proceso -que puede contener luengos periodos de latencia antes de producir un tipo de sismicidad perceptible- podrá estar relacionado, entre otros, con modificaciones contextuales, así como también, de manera significativa, con los cambios producidos al interior del movimiento en cuanto a su particular análisis de la realidad, es decir, cambios en sus marcos interpretativos. Es desde esta perspectiva analítica que abordaremos el giro movi- mental que parece haberse verificado en Lumako, el cual, a su vez, pareciera responder a un proceso de mapuchización de la lectura de la realidad en directa vinculación con componentes contextuales específicos. La articulación conceptual y práctica de los elementos antes mencionados viabilizaron el surgimiento de un Movimiento Mapuche Autonomista que parecía remitir a una búsqueda del Mundo y del País Mapuche -aunque no necesariamente se articularan discursivamente de ese modo- como una manera de enfrentar el continuum histórico de dominación, ya no solo expresado en una negación originaria, sino que también en la segunda negación. La negación originaria alude al proceso multifacético materializado en el siglo XIX desde el Estado chileno y que culminó con la ocupación mi- 
litar del territorio mapuche. La segunda negación, por su parte, dice relación con la imposición en la década del setenta del modelo neoliberal. Y es precisamente ante la aparente búsqueda desde el poder chileno de la obliteración definitiva del territorio Movimiento Mapuche parece haber iniciado su propia búsqueda de la (re) construcción de su Mundo y su País, como un medio de contra-negación, que es otra forma de afirmación. En este caso, al menos en parte y en un primer momento, se trataba de una afirmación étnica y cultural, pero también política, a través de la cual el movimiento se ponía en movimiento una vez más.

Lo hizo a través de la recuperación de dos predios considerados usurpados y la quema de dos camiones pertenecientes a la Forestal Bosques Arauco, lo que provocó una explosión que estremeció los cimientos del sistema de relaciones sociales imperantes, transformando, tal vez de manera irreversible, el modo de relación que se había configurado entre el Estado y sociedad chilenos y el pueblo mapuche. Pero, también, los eventos de Lumako constituyeron un implosión en el propio Movimiento Mapuche, puesto que Lumako se puede entender como fin y comienzo de un proceso, un punto de inflexión en el desarrollo del Movimiento Mapuche Autonomista. Y como todo punto de quiebre, no remite ni puede ser reducido a pu eventoúnico, sino que a un conjunto de monentos, pues pocos tos, pues pocos procesos historicos son unilineales claramente demarcados en periodos o eventos precisos, por lo tanto, se interrelacionan y superpone momentos y situaciones, acciones y marcos analíticos que interpretan y expresan la realidad. Empero, aun así, es posible sostener que Lumako constituye un giro movimental en el contexto general de un proceso de confrontación de ideas, de estrategias, liderazgos, repertorio de acciones y demandas de su acción corepertorio de acciones y demandas de su acción colectiva, todo lo cual es susceptible de ser analizado desde los conceptos centrales de Estructura de Oportunidades Políticas y de Marcos Interpretativos. Lo anterior nos permitirá visualizar de mejor manera el proceso de mapuchizacion agenciado por el Movimiento Mapuche Autonomista.

\section{El desencanto mapuche con la transición o la transición del movimiento}

El componente autonómico en la demanda mapuche no es nuevo en la historia del movimiento,

aunque solo en los últimos lustros parece haber adquirido su centralidad y, para explicar dicha centralidad, es importante analizar aquellos elementos contextuales diacrónicos y sincrónicos, algunos históricamente más lejanos y otros relacionados con coyunturas mas recientes. En estén úlino caso, pare ceyunturas mas recientes. En estél tho casoce importante, desde las teorías de los movimientos sociales, graficar y establecer los componentes contextuales articulados en la idea de Estructura de Oportunidades Políticas (McAdam, McCarthy y Zald, 1999; Tarrow, 1998; Tilly, 2002; Ibarra, 2005) dimanados del proceso transicional desde dictadura a democracia. La Estructura de Oportunidades Políticas alude a aquellus cimensiones de contexto, de s de contexto, de indole esencialmente coyuntural, pero también de carácter más permanente, que -en su articulacióngeneran modificaciones en el cuadro político que, a su vez, incentivarían la acción colectiva o, más específicamente, el surgimiento de un movimiento social, puesto que este nuevo cúmulo de circunstancias allanaría el camino para la participación en la acción colectica y reduciría el costo de la misma. Es decir, se intenta explicar la emergencia de un movimiento mediante la observación y análisis de la interacción entre este y la institucionalidad y, especialmente, en los cambios materializados en dicha institucionalidad o en las relaciones informales de poder (McAdam, McCarthy y Zald, 1999). Algunas de las dimensiones consideradas importantes por Tarrow serían:

"la apertura de acceso a la participación de nuevos actores; las pruebas de nuevas alianzas politicas en el seno del gobierno; la aparición de aliados influyentes; la aparición de divisiones entre los dirigentes; $y$ una disminución de la capacidad o la voluntad del Estado de reprimir la disidencia" (Tarrow, 1998: 116).

En el caso concreto de nuestro país, parece evidente que la transición desde un régimen dictatorial hacia uno de carácter democrático inicialmente generaría un conjunto de oportunidades para los movimientos sociales, duramente reprimidos durante la dictadura militar, en el ámbito de la expresión y satisfacción de sus demandas y reivindicaciones. $\mathrm{Y}$ las expectativas del movimiento mapuche -algunas de ellas consignadas en el Acuerdo de Nueva Imperial ${ }^{3}$ - parecían basarse en un análisis de la realidad que percibía estas oportunidades. En primer lugar, un gobierno que expresaba a un régimen político por construirse que, a diferencia de la dictadura, estaría basado en el respeto a los derechos humanos y, por lo mismo, poseería la voluntad política de evitar el recurso a la violencia para reprimir la protesta social. En segundo término, la emergencia de fisuras en la elite en torno a la forma de entender el tema de la relación chileno-mapuche, y el surgimiento, o más precisamente, en niveles clave, de un núcleo significativo de intelectuales, profesionales y políticos indigenistas o que profesaban simpatía o comprendían la necesidad de reconocer los derechos de los mapuche. O, incluso, eran partidarios de la libredeterminación de los pueblos indígenas. En tercer lugar, en una lista no exhaustiva de elementos contextuales importantes, entre los cuales se hallan algunos se hallan diseñados para enfrentar la problemática indígena, es decir, la elaboración de una nueva Ley Indígena y la creación de la Corporación Nacional de Desarrollo Indígena, por ejemplo. Además, por cierto, del restablecimiento de mecanismos democráticos de expresión y las consiguientes posibilidades de organización, movilización, interpelación y acceso a los poderes del Estado.

Ahora bien, si evidentemente los factores contextuales o externos al movimiento son importantes y, por lo mismo, deben considerarse como elementos de análisis en la emergencia y posterior desarrollo del movimiento mapuche actual, la focalización solo en tales elementos puede tender a distorsionar o unilateralizar la lectura de la realidad y la comprensión de la acción colectiva. Se dan al menos otros tres componentes que pueden limitar el valor analítico de la Estructura de Oportunidades. Primero, se puede minimizar, subestimar o simplemente ignorar la propia capacidad del movimiento para generar la mencionada Estructura. Segundo, la EOP es estatocéntrica, es decir, "de la centralidad del Estado $y$ sus instituciones como referencia fundamental para comprender las formas de acción colectiva de los movimientos y su historicidad..." (Iglesias, 2007:69) emerge la arquitectura de la EOP. Tercero, cuesta-se puede argumentar- discriminar entre una estructura, entendida como una articulación de elementos claramente precisables y definibles, de meras "oportunidades políticas" (Ibídem: 70).

Además el énfasis unilateral y reduccionista en la EOP no puede explicar por qué en un mismo contexto de cambios institucionales surgen algunos movimientos sociales y otros no. Claro ejemplo de ello lo constituye el proceso transicional en nuestro país, puesto que si bien es cierto que sus particularidades podrían explicar en parte el surgimiento del movimiento mapuche, no puede dar cuenta de no emergencia de otros movimientos que podrían haber representado los intereses o reclamaciones de otros sectores sociales. Por todo lo anterior, para intentar relacionar la negación originaria, la segunda negación y el resurgimiento mapuche, es menester analizar también elementos de carácter interno al movimiento que habrían posibilitado o vehiculizado a construcción del movimiento y particularmente, lo que podría denominarse su visión mapuche de la realidad, que contrastaría notoriamente con la visión chilena de la realidad, produciéndose, por lo tanto, una confrontación de visiones, de identidades, de culturas, de proyectos de país. El Estado chileno lo llama conflicto mapuche el movimiento mapuche lo llama dominación y derecho a la libredeterminación. Y, para arribar a los planteamientos, demandas, propuestas y discursos actuales, en e seno del movimiento mapuche -es posible argüir- se articularon singulares procesos de enmarcamiento desde la década de los setenta, pero fundamentalmente en las dos últimas décadas, que compendían expresan la reflexividad del movimiento, en otras palabras, la capacidad para pensarse y repensarse a sí mismo en función de comprender y accionar en contextos históricos diversos.

\section{Marcos interpretativos: en búsqueda}

\section{del País y del Mundo Mapuche}

La alteridad, desde el punto de vista chileno, era la mismidad para los mapuche y ésta se constituí desde la memoria antigua. Por ende, los marcos de análisis del movimiento, aquellos que les permitían interpretar la relación con la sociedad chilena y la nueva realidad, se construyeron, al parecer, desde la mapuchidad y estableciendo fronteras identitarias más precisas vis a vis las fronteras wingka. Y es mapuchidad se nutría de la cultura, se refugiaba en la tierra y se anclaba en el territorio ancestral para convertirse en movimiento; era, por decirlo de al guna manera, identidad en movimiento, cultura en movimiento, memoria en movimiento, tierra en movimiento $y$ territorio en movimiento, Para algunos autores (Mc Adam, Tarrow, Tilly, 2001), los procesos de enmarcamiento no se deben reduci solo a la categoría de estrategia movimental, sino que deberían entenderse como involucrando

"la construcción interactiva de disputas entre contendores, sus oponentes, elementos del Estado, tercera partes y los medios de comunicación. El contexto politio en el cual se construye un movimiento contribuye enmarcar sus demandas; los medios y otras fuentes de comunicación inadvertidamente enmarcan a un movimiento para sus participantes, así como también para 
otros. Los recursos culturales limitan y moldean los esfuerzos enmarcadores de carácter deliberado de parte de los dirigentes del movimiento" (Ibídem: 44) ${ }^{4}$.

Efectivamente, uno podría vincular el resurgimiento del movimiento mapuche con la imposición del modelo neoliberal en la década del setenta, la consolidación del mismo durante los gobiernos democráticos, y la imbricación con todos los procesos anteriormente mencionados. En otras palabras, con el contexto transicional pactado, la elaboración de leyes e instrumentos institucionales que, al menos en temas centrales, desilusionaron a parte importante del movimiento mapuche; el rol de los medios de comunicación que, en su mayoría, eran críticos de los mapuche y de sus demandas; las empresas forestales y particulares que ocupaban tierras indígenas que, por cierto, se oponían a las reclamaciones mapuche. Y, también, actores políticos, individuales y colectivos, que decidían, influenciaban o implementaban la agenda indígena. No bstante, en la aserción de los mencionados autoes, pareciera persistir la adscripción de mayor peso específico a componentes externos que a aquello de índole interna, incluso señalando las limitaciones de los recursos culturales para la construcción de marcos interpretativos. Si bien es cierto que uno podría compartir la idea de que los procesos de enmarcamiento no se pueden reducir o atribuir strategias de estamentos dirigenciales o, más aún, grupo de dirigentes en particular, no es menos cierto que en el caso de los movimientos indígenas, y el mapuche no es excepción, la dimensión cultural interna adquiere una relevancia fundamental que pareciera transcender motivaciones instrumentales para establecer una arquitectura de sentido para la acción colectiva. Por lo mismo, parece importante y necesario entender que

"la combinación de oportunidades politicas y estruc turas de movilización dota a los grupos de un cierto potencial para la acción. Sin embargo, la unión de estos dos elementos resulta insuficiente para explicar fenómeno de la acción colectiva. Existe un elemento mediador entre oportur mediador entre oportmidad, organizacion y acción, saber, los significados compartidos y conceptos por medio de los cuales la gente tiende a definir su situación (McAdam, McCarthy y Zald, 1999: 26).

Sería, por lo tanto, un proceso consciente de construcción de la otredad, de interpelación a la significación o asignificación hegemónica chilen Sería por consiguiente, un proceso de resignificación de lo mapuche, de rescate cultural identitario, aunque ello no implica -en términos lateralismo culturalista que ignore los aspectos de tipo estructural o económico" (Iglesias, 2007: 56). Por el contrario, remite más bien a intentar entender la interelacion de todos estos factores y valonfactores y valorar el componente culturalista como importante en la comprensión de los movimientos indígenas y, más precisamente, en la construcción y desarrollo de marcos interpretativos que reivindican, reestructuran o rearticulan saberes y prácticas ancestrales, las transforman en discursos, demandas y repertorio de acciones que, en lo sustancial, interpelan al paradigma de la modernidad imperante mediante el recurso a elementos cosmovisionales, cosmogónicos, mnemónicos, territoriales, telúricos, étnicos y nacionalitarios. Lo anterior conlleva un énfasis teórico distinto y un desplazamiento analítico para intentar aprehender la especificidad del movimiento mapuche actual desde el movimiento, o al menos desde parte significativa de sus dirigentes y militantes. No se ignoran ni subestiman los componentes contextuales, sino que más bien se aquilatan los componentes movimentales internos como importantes y analíticamente útiles. Pero, también, requiere explicitar y puntualizar al menos los siguientes puntos. En primer lugar, el reconocimiento de los elementos mencionados: cosmovisionales, territoriales, mnemónicos, entre otros, no debe entenderse como el asumir su univocidad, centralidad o perifericidad en su ubicación discursiva, sino que más bien constituye una constatación de su recurrencia en los marcos interpretativos del movimiento mapuche a partir, especialmente, de la década del noventa. En segundo lugar, no todas las organizaciones mapuche consideradas parte del movimiento, o que se autodescriben como integrantes del mismo, recurren simultáneamente o de manera similar a la elaboración de marcos analíticos que incorporan los elementos señalados. En tercer lugar, y relacionado con lo último, no existe -ni podría existir- una lectura única u homogénea de la realidad, aunque la situación empirial parecía requerir de una relectura vis a vis otros momentos historicos que, a su vez, necesitaba trazar, en los procesos de enmarcamiento y en la elaboración de discursos y estrategias, la politización de la demanda o la culturización de la política.

En síntesis, el Movimiento Mapuche Autonomista surgido en Lumako constituye una expresión concreta de un segmento del pueblo mapuche que, en su pluralidad, ha elaborado marcos interpretativos -aquellos prismas que descomponen y reordenan la realidad- que han politizado la cultura o culturalizado la política, identificando al Estado chileno $y$ al modelo neoliberal como los responsables de un 政 sistemática del pueblo mapuche. Posee un discurso autonómico sustentado en las ideas de Mundo y País Mapuche y un alto grado de integración simbólica cimentada en la mapuchidad, accionanda a través de medios convencionales y no convencionales de lucha. Todo lo anterior, es posible argüir, es producto del proceso de mapuchizacion de sus marcos Deren logrado el objetivo de reducir el grado de complejidad de la realidad focalizando la mira del movimiento en el Estado y el modelo neoliberal, fundamentalmente simbolizado en las empresas forestales, y por el otro, motivando a la acción colectiva, precisamente por la simplificación de una problemática compleja. Pero, además, porque el mencionado proceso de mapuchizacion fortal nencia, de origen comun y de historia por const nencia, de origen común y de historia por construir desde lo mapuche.

\section{Pensándose como mapuche desde}

\section{lo mapuche}

Un elemento definitorio fundamental parece ser la centralidad del pensamiento mapuche o rakizuam ${ }^{5}$ y, en su expresión política, el pensarse como mapuche y desde lo mapuche en la conformación del movimiento. Ello no significa que anteriormente los mapuche en el siglo XX e incluso en el acturtno hayan reflexionado desde lo mapuche o que el movimiento actual, y particularmente su liderazgo, sean lo único verdaderamente mapuche y no occidentalizado. De hecho, los mapuche reconocen el rol desempeñado por aquellos líderes mapuche que, en distintas épocas y por diversos medios, bregaron por la defensa de los intereses de su pueblo desde "lo mapuche" (Quilaqueo, 2009 , entrevista personal; Penchuleo, 2009, entrevista personal; Mariman Pablo, 2010: Caniuqueo, 2010, entrevista personal) Por lo tanto, lo que se quiere significar, más bien, es que en su reflexión, el movimiento autonomista comienza a cuestionar su antigua relación con actores políticos y sociales no mapuche; cuestionándose, al mismo tiempo, los distintos diseños estratégicos que, según su percepción, no habían producido un cambio sustantivo en la situación del pueblo mapuche. Por ello, el movimiento sugiere, que

"en algún momento se produjo un quiebre, una suerte de determinación para que un grupo de dirigentes de comunidades y personas de una comunidad hayan dich iesto no da para más! y vamos a comenzar a trabaja de otra manera. Entonces, ese proceso que se inició con esa quema de camiones se debió a que había una situación que no se podía sostener, que se relacionaba con la lengua, costumbre y cultura, pero también asociada a una situsion de sequia, de fatra de oporien a una sing

$Y$ ese quiebre al que se alude, para los mapuche parecía estar claramente relacionado con un proceso centenario de dominación y negación y, simultáneamente, con una nueva forma de negación con la penetración del modelo neoliberal en territorio maa pobreza y reproducía de modo mpliado la marginalidad de las comunidades en el modelo de desarrollo diseñado para la región. A este nuevo arreduccionamiento, acorde a la lectur realizada por el movimiento, había que enfrentarlo de otra manera

"y dar una señal para el Estado y también para el pueblo mapuche, así la decisión de hacer esa acción es una señal de que cuando los temas no avanzan hay que dar ciertas señales de inconformismo. La quema de camiones de las forestales significa que para los mapuche de ese territorio, como para muchos otros, las forestales se tenian que ir del territorio mapuche, porque para nosotros esos son los principales enemigos, $y$ to las mineras, o las salmoneras que están directamente afectándonos a nosotros los Lafkenche ${ }^{6 "}$ (Vilches, 2010, entrevista personal).

Pero, fundamentalmente, uno podría colegir, constituía una faro de alerta al interior del movimiento, porque la deflagración interna o la onda expansiva pareció remecer certezas y prácticas políticas históricas para proponer, desde un nuevo proceso de enmarcamiento, el distanciamiento de los partido políticos chilenos, la territorialización del acciona colectivo y de la demanda, así como la utilización de métodos no convencionales de lucha. Por sobre todo, significó un desplazamiento hacia una visión licto. podría hablar de un renacimient mapuche. Fue, de alguna manera, según los pro- 
pios mapuche, una resignificación y revalorización de lo mapuche, el

"comenzar a creer que los mapuche podiamos luchar frente a una empresa que era concreta, como lo era una forestal. Lumako elevó la moral en mucha gente mapuche. Y también permitió aclarar un poco las aguas en relación hacia dónde iba el Movimiento Mapuche, porque se vio, por ejemplo, a un movimiento que se subordinaba ideológicamente al pueblo mapuche. Además, los sectores de izquierda no creían que el pueblo mas, los sec mapuche pudiera generar una accion de esa envergadura que, si uno lo mira más detenidamente, a lo mejo no fue tan espectacular, pero sí significativa. Y en la época en que vivíamos, en un gobierno que se suponía democrático, el pueblo mapuche plantea que la realidad nuestra era distinta. Y en ese sentido Lumako es sumamente importante para el impulso de esta ûltima lucha que estamos viviendo. Además, esta acción concreta la

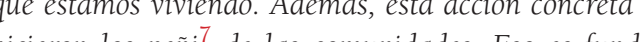
mental! (Huenchunao, 2010, entrevista personal).

Este último aserto no es menor, pues la territorialización de las movilizaciones implica un viraje sustancial en la acción colectiva que está en directa relación con modificaciones en los marcos interpretativos, es dable sostener, porque priorizan algunos elementos seminales de lo que podría denominarse como Mundo Mapuche y País Mapuche, cambiando tanto el prisma que descompone la informe realidad, como la recomposición de la misma en una especie de mapuchización de la realidad y, simul táneamente, del movimiento. En cualquier caso, las referencias al Mundo y País Mapuche, no surgieron en Lumako, pues siempre han estado presentes -aunque no necesariamente sintetizatas en dichos - counche conceptos- en el discurso del Moviniento Mapuche historico. Incluso en tiempos recientes, con antelación a los sucesos de Lumako, en alusión a probable establecimiento de una comunidad mapuche urbana en Temuco, se puntualizaba que en esta comunidad

"se recrea y se proyecta un estilo de vida y de valores de convivencia particulares al mundo mapuche; se reconstituyen los lazos de solidaridad y reciprocidad entre los miembros de nuestro pueblo, se trata de recuperar el espacio territorial mapuche en las grandes ciudades, implementar un proyecto de vida, con territorio propio, autoridades mapuche, con valores, principios y reglamentos propios del mapuche. Creemos que es una nueva alternativa de vida, de lucha, de sobrevivencia y de proyección de nuestro pueblo. Para crear conciencia de la existencia de un un mundo distinto, es necesario realizar un trabajo de horm (Marileo y Caquilpan, citado en Tricot, 2006:32) Es decir, aquí se entrelazan tres elementos claves: El carácter no espontáneo del movimiento del movimiento; el tipo de relación entre el movimiento y las comunidades y, finalmente, la forma de (re) construcción del Mundo y País Mapuche. Es en este marco determinado que se asume la no espontaneidad del movimiento y la concomitante necesidad de una labor previa de concientización, por lo que para algunos dirigentes había que entender que

"Lumako es una cosa que se venía trabajando desde el año 90, creando un poco de conciencia, de responder ¿Quiénes somos realmente? Y ese es el trabajo que nos fue convirtiendo en sujetos protagonistas de todo el proceso. Muchos dirigentes salieron de aquí, y dentro del territorio Nagche: Pascual ${ }^{8}$, Aniceto ${ }^{9}$, Chureo ${ }^{10}$, Victor Ancalaf ${ }^{11}$. Y así se fue sumando más gente, que fue producto de estas discusiones que veniamos haciendo del año 90 en adelante; visita en las casas, generando conciencia de a poco. Que la comunidad, y después los jóvenes, se atrevieran a llevar adelante esta nueva estrategia; una estrategia propia donde había que cumplir roles, estar dispuesto a caer preso si era necesario, dar la cara ante la autoridad, no conformarse más con solidaridad o con el asistencialismo, sino que armar algo propio" (Reiman Galvarino, 2009, entrevista personal). Lo anterior de alguna manera sintetiza el giro movimental verificado en Lumako, porque superó el conformismo y la aceptación de una situación prolongada de marginalidad y dominación y, también, de dependencia de otros actores políticos en la conducción de la acción colectiva o en la elaboración de propuestas y estrategias (Ibídem). Antolín Curriao, longko de Quepuka Ralko ${ }^{12}$ en el Alto Bío-Bío, reforticular que afectaba a su territorio, destacaba elementos similares a Lumako señalando que

"todas las comunidades estamos unidas. Estamos lu-

Hermano en mapudungun. Término habitual entre los mapuche para referirse a otros mapuche.

Pascual Pichun, longko de la comunidad Antonio Niripil en Temulemu.

9 Aniceto Norin, longko de la comunidad Lorenzo Norin, en Didaico.

10 Dirigente de las primeras movilizaciones en Lumako.

11 Dirigente de la comunidades de Collipulli.

12 Una de las dos comunidades directamente anegadas por la represa Ralko, la otra es Ralko Lepoy.

chando, no estamos solos. Estamos muy gratos de su apoyo, que vengan a darnos anhelo. Nunca nos habiamos unido tanto, estar de acuerdo en luchar conjuntamente, hacer una sola masa. La unión es lo que hace la fuerza Somos nosotros los que tenemos que levantarnos primero. Aquí no tenemos que ver con ninevin partido, es por la a. Si nos unimos el golpe va a ser fuerte" (Curriao, 1997, entrevista personal).

Asimismo, señalan los mapuche, se superó "el miedo que existía de reivindicarse, de atreverse, de enfrentar la persecución policial posterior . " (Reiman Galvarino, 2009 , entrevista personal). En este sentido, la labor dirigencial y de otros activistas parece haber sido determinante en la transformación rece haber sido determinante en la transformación
del descontento y la frustración en acción colectiva. Especialmente importante fue la labor política realizada por una nueva generación de dirigentes que, algunos en las comunidades, otros desde los Hogares Mapuche y algunos en organizaciones mapuche en las ciudades regionales, inician un potente proceso de resignificación de lo mapuche. Todo lo anterior influenciado, también, según un importante dirigente mapuche, por un contexto continental particular donde

"los más jóvenes, los estudiantes, fuimos dándonos cuenta de nuestra situación. Y otros sectores también ayudaron a que viviéramos ese cambio. Por ejemplo, el tema de los 500 años, el levantamiento de los zapatistas, ayudaron mucho para que se generara un nuevo aire dentro de las movilizaciones o del movimiento mapuche. Concretamente, yo creo que se levanta un nuevo movimiento, que es mucho más autónomo no subordinado ideológicamente a otras entidades que no sean propias del pueblo mapuche. (Huenchunao, 2010, entrevista personal).

Entonces, si bien es cierto se valora e impulsa la participación activa de la comunidad en las discusiones y en el proceso de toma de decisiones con respecto a la acción colectiva, se asume la necesidad de un trabajo previo de persuasión y debate orientado por los propios comuneros. Es interesante, no obstante, que parte significativa del movimiento en Lumako no visualiza o concibe dicho trabajo como la labor de una vanguardia al antiguo estilo de la izquierda chilena o latinoamericana ${ }^{13}$ según los propios mapuche (Huenchunao 2010, entrevista personal; Caquilpan 2009, entrevista personal ; Curihuentro Claudio, 2009, entrevista personal; Painecura,
2010, entrevista personal ; Reiman Alfonso, 2000 entrevista personal), sino más bien como una necesidad en la perspectiva de la construcción de estructuras organizativas más masivas y participativas a nivel comunitario. En este sentido, si bie experiencias o incluso de exame exhaustivo de discursos o prácticas exógenas, pareciera constatarse un símil con la conceptualización zapatista de su rol político. En diversos documentos el EZLN ha aludido al carácter de su relación con el movimiento zapatista, con otras organizaciones con los pueblos de México, así como también de su trabajo de décadas de aprestamiento para su eventual irrupción en 1994. Los zapatistas han puntualizado, por ejemplo, que ellos no pretenden

"ser la vanguardia histórica, una, única y verdadera. Nosotros no pretendemos aglutinar bajo nuestra bandera zapatista a todos los mexicanos honestos. Nosotros ofrecemos nuestra bandera. Pero hay una bandera más grande y poderosa bajo la cual podemos cobijarnos todos. a bandera de un movimiento nacional revolucionario donde cupieran las más diversas tendencias, los más diferentes pensamientos, las distintas formas de lucha, pero solo existiera un anhelo y una meta: la libertad, la democracia y la justicia" (EZLN, 20 de enero, 1994).

Es más, en la afirmación: "Para todos todo, nada para nosotros", pareciera sintetizarse el concepto de democracia política del EZLN, planteamiento refrendado por la cristalina declaración donde se sostiene que los zapatistas

"hemos aprendido a hablar y a escuchar, a caminar sin exclusiones, a respetar los distintos niveles y pensamientos, a no imponer nuestras ideas y a no decretarle obediencia a la historia, pero sobre todo a reconoce y corregir nuestros yerros. Y es de ustedes de quienes hemos aprendido todo esto. Ustedes nos han enseñado que no estamos solos, que nuestra verdad no se puede imponer como verdat absoluta. Que conocer nuestros errores no nos hace más pequeños y que hablar de nuestras fallas no ensucia nuestras palabras. No pocas veces hemos hablado y actuado como si la verdad y la razó no tuvieran otro lugar que el nuestro, como si fuéramo poseedores del camino mejor, como si fuéramos los únicos y los mejores. Hemos herido a gentes buenas, pero no por soberbia. Aprendiendo nos vamos formando haciendo nuevos" (EZLN, 25 de agosto, 1995).

Entonces, la participación de la comunidad, la consulta permanente, el debate de estrategias y 
formas concretas de la acción colectiva parecían ser elementos componentes articuladores valiosos de la relación entre el movimiento y los pueblos indígenas, Y, en el caso específico de Lumako, se percibe algo similar sin obviar, por cierto, la declapara necesidad de proceso de concientización desde un segmento más poli-
tizado de la misma comunidad. Es decir, para los tizado de
mapuche

"la participación activa de las comunidades fue lo fundamental en todo el proceso, y no fue fácil, nos llevó damental crear conciencia de la necesidad de luchar por la reivindicación de esos derechos. Hubo un paciente trabajo con las familias, con los longko de distintas comunidades. La idea fue siempre que la gente no solo esperara cosas, sino que elaborara su propia estrategia de recuperación de tierras. Por eso, los eventos de Pichilonkoyan y Pililmapu son la culminación de un proceso $y$ al mismo timpo, 1 inicio de una nueva pa en nuestra personal)

Empero, esta nueva etapa -sostienen en el movimiento- no estuvo exenta de conflictos de liderazgo, protagonismos individuales y colectivo que socavaron tanto la credibilidad como el discurso unitario de dirigentes mapuche y, además, contribuyeron para que el gobierno intentara debilitar al naciente movimiento autonomista, no solo a través de la represión, sino que también mediane la cooptación. De hecho, en el mismo Lumak crearon organizaciones paralelas, como la Unión de Comunidades Autónomas de Lumako -con generosos recursos financieros, vehículos y sedes- cuy finalidad era conf la Asociación Ñankucheo que a la sazón, aparecía como uno de los espacios importantes, aunque no el único, de generación de liderazgo y conducción del movimiento en ese territorio. Asimismo el gobierno del presidente Frei impulsó los "Diálogos Comunales" que explícitamente excluían cualquier comunidad que estuviera involucrad en conflictos $\mathrm{O}$ sea dejaba fuera a los principaes actores de la situacion de agravio, negacipales actores de la situacion de agravio, negación dominación chilenas. Sin embargo, eventualmen te se aprobó el Pacto por el respeto ciudadano subscrito en La Moneda y destinado a "inaugura una nueva convivencia entre todos los pueblos, comunidades y personas que compartimos $\mathrm{CO}$ tidianamente este territorio anclado al sur de la Tierra" (Citado en Buendia, 1999: 17). Es más, ni siquiera las empres  en el conflcto chileno-mapuche, subscribieron el acuerdo. En todo caso, a los mapuche, como sos- tiene Santos Reinao, quien fuera presidente de la Corporación de Comunidades Mapuche del Lago Lleu-Lleu, "siempre se nos han impuesto soluciones y proyectos desde afuera, nunca se nos ha pedido la opinión. Debemos ser capaces de ser los actores principales en cualquier proceso de desarrollo, porque somos nosotros los afectados, los que sufi(ostas, los que sufrimos la pobreza, el hacinamiento, la fal
(Reinao, Citado en Buendía, 1998:10).

No obstante, la voluntad o declaración de intenciones de ser los actores principales no exime al Movimiento Mapuche Autonomista de dificultades, contradicciones, confrontación de opiniones, divergencias y diversidad de métodos de acción. Las críticas de fundamentalismo étnico o nostalgia cósmica que supuestamente caracterizarían a algunas organizaciones, como el Consejo de Todas las Tierras (Mariman, José, 2003), se contraponen, por otro lado, a críticas para con el entreguismo, claudicación y negociaciones con el Estado que supuestamente describirían a otras. Estas últimas críticas, fundementibinas de la Coordinadora Arauko-Malleko, implican, a su vez, un cierto grado de mesianismo y sectarismo por parte de la CAM, lo cual es objeto de críticas desde otros segmentos del movimiento autonomista, incluso de aquellos que en algún momento formaran parte de esta, o al menos, compartieran sus lineamientos centrales. La organización mapuche urbana Meli Wixan Mapu, vinculada a la CAM, se distanció de esta el 2005, señalando:

"la CAM tenía una práctica politica que acentuaba el aislamiento de la organización respecto al conjunto del movimiento mapuche, ya que muchas veces se planteaban, en una actitud egoísta, como detentadores "exclusivos" de ciertas definiciones autonomistas". (y)... lamentablemente, todas aquellas personas que intentaron plantear sus molestias, críticas politicas y dudas fueron víctimas de fuertes descalificaciones, tendientes a invalidar sus opiniones y a crear un manto de desconfianza" (Meli Wixan Mapu, 2005).

Por su parte, la Coordinadora es categórica en su rechazo a dirigentes y organizaciones que, acorde a su percepción, negocian con el gobierno, puesto que "son propuestas que desestructuran y demuestran la poca confianza que tienen algunos dirigentes en nuestro propio pueblo" (CAM, 2001, entrevista personal colectiva). Las críticas al supuesto mesianismo y aspiraciones vanguardistas, que no se condecirín con la noción de una relación simética y democrútica con las comunidates, parecen recen do señala: "queremos ser la organización real para nuestro pueblo. Desde la derrota político-militar en el siglo XIX -la mal denominada Pacificación de la Araucanía- no ha habido una organización con línea histórica de esencia mapuche" (Ibid.). Además, estipulan

nuestro proyecto político está basado en valores, y estos valores de justicia, libertad, solidez, tienen que darse en la práctica; la autonomía se construye y se consolida hoy. Tratamos de ser consecuentes con estos valores de integridad moral, aunque, por supuesto no somos perfectos, pero tratamos de guiarnos por estos principios. El caudillismo no tiene espacio dentro de nuestra cultura, cada longko o dirigente no pelea por ser un héroe o un segundo Leftraru, simplemente luchamos por lo que creemos es justo. Y aquellos que se apartan de esta linea dejan de pertenecer a la Coordinadora, porque no aceptamos infulas de poder o afanes de protagonismo. Para nosotros es importante respetar la estructura tradicional y subordin es subestimar a nuestra gente; también es importante decir que nuestros militantes, nuestros cuadros, no están en Temuko o Concepción, sino que directamente en las comunidades" (Ibídem).

En el maremágnum de declaraciones y posiciones contrapuestas se halla una miríada de organizaciones, comunidades, comuneros y mapuche en general que aparecen más como observadores que como partícipes de debates que poco o nada tienen que ver con sus graves problemas de subsistencia (Cayuqueo, 2009, entrevista personal; Painemal, entrevista personal, 2009; Painecura, 2010, entrevista personal). En cualquier caso, los movimientos sociales, constituidos en la heterogeneidad, aunque interrelacionados por demandas centrales comunes, son tanto espacios de convergencia y articulación reticular como de debate y confrontación de liderazgos y estrategias. Además, históricamente, el movimiento mapuche se ha caracterizado por su diversidad y ausencia de una organización o estrategia únicas, aunque pareciera que en Lumako se materializaron cambios sustantivos en los marcos analíticos del movimiento autonomista que mapuchizaron la lectura de la realidad, politizando la cultura o culturizando la política.

Especialmente significativo en el marco de esta nueva forma de entender la acción colectiva y las eventuales movilizaciones es la recomposición de estructuras propias del pueblo mapuche en el ámbito político y social o lo que algunos denominan la estructura tradicional mapuche antigua (Painecura 2009, entrevista personal; Huilcaman, 1992). Aqui, no obstante, en la práctica política concreta pareciera manifestarse una cierta contradicción, toda vez que el Movimiento Mapuche Autonomista, o al menos parte de este, busca refortalecer, resignificar y revalorar el rol de algunas expresiones específicas de las estructuras mapuche-como por ejemplo el rol de los longko, machi y werken- y por otro lado aquella nueva generación de dirigentes no eran necesariamente ni longko, ni machi ni werken, aunque muchos al fragor de la brega se convirtieron en estos dos elementos importantes para intentar comprender los procesos de enmarcamiento en general y, má específicamente, el rol del movimiento y la relación entre movimiento y pueblo mapuche: Por una parte, la reconstrucción de estructuras antiguas y, por el otro, la conceptualización del movimiento. En relación al primer punto, la interrogante principal es, por cierto: ¿Cuáles estructuras antiguas son las susceptibles de ser reconstituidas y, simultáneamente, a qué referente histórico nos remite el proceso reconstructor? O, visto desde otro ángulo: ¿Se trata de un proceso reconstructor riguroso e invariable o, por el contrario, se hace referencia a un proceso más flexible de recuperación de algunos elemen tos selectivos de algunas estructuras en función de un enmarcamiento que otorgaba un rol pivotal a las autoridades mapuche? Y, tal vez la pregunta más importante: ¿Deseaban dichas autoridades ser parte del mencionado proceso (re)constructor o fueron parte constitutiva e integral del mismo? Las respuestas a tales interrogantes no son unívocas y quizás no podrían serlo, puesto que los movimientos sociales se constituyen en la pluralidad y, por lo mismo, sus lecturas de la realidad, su diagnóstico y definición de estrategias son disímiles, aunque pueda haber concordancia en elementos centrales como lo son la identificación de una relación asimétrica con la sociedad chilena, la concomitante y sistemática negación del mapuche por parte de esta y sin duda, la peligrosa negación que conlleva la implantación del modelo neoliberal de apropiación territorial. Lo que sí parece evidente es que por una multiplicidad de causales, de acuerdo a los mapuche, la mayoría de las autoridades mapuche habí permanecido inactiva o sus acciones reprimidas u ocultas y circunscritas a ciertas prácticas culturales,

4 Muchos de los actuales werken son jóvenes; incluso la "nueva dirigencia" emergida en Lumako ha dado paso -o ha sido sobrepasadapor una nueva generación de líderes. 
como Nguillatun ${ }^{15}$ y Machitun ${ }^{16}$, por ejemplo, durante el luengo período dictatorial y, también, antes de ello (Painemal, 2009, entrevista personal; Panchillo, 2009, entrevista personal; Cayuqueo, 2009, (iempre estuvieron presentes, aunque dramáticamente reducidos sus campos de acción producto de la ocupación chilena y la desarticulación del Mundo y País Mapuch impulsada desde la elite chilena. En este contexto, no deja de ser interesante que, por una parte, se rescatara y resaltara en el discurso mapuche la importancia de los longko y por otra, que uno de los principales dirigentes surgidos en Lumako al menos en sus etapas iniciales, fuera un joven evangélico, lo cual ilustraría el hecho de que existía una situación nsostenible y, afirman los mapuche, "más allá de que si uno hable o no la lengua o vista poncho, ah en Lumako se daba una situación de sequía, de falta de oportunidades, de pobreza, de una serie de conflictos inaceptables" (Painecura, 2010, entrevista personal). Ello es ratificado en el ańlisis rea do por dirigentes de la CAM que en relación a las movilizaciones de esa época y de la supuesta radicalización del movimiento mapuche, señalan:

"probablemente el elemento de violencia cobra notoriedad, pero la violencia no es engendrada desde las comunidades o desde fuera: es una violencia generada estructuralmente por el sistema, cuando las comuidades no tienen tierra y la gente pasa hambre; cuando no tienen agua, como en los casos de Lumako y Puren; cuando no tienen salud y acceso a nada; cuando existe una situación de desarraigo, de crisis estructural, cuando las mujeres se van de las comunidades y no quieren tener hijos porque no bs pueden criar por la pobreza. Eso es violencia" (Llaitul, entrevista personal, 2011).

En otras palabras, de alguna manera la lectura de la realidad trascendía posiciones políticas o ideológicas y se situaba en el ámbito del sentido común. Sin embargo parecía necesario realizar -como se ha señalado- un trabajo político de organización toma de conciencia que transcendiera experiencias individuales o incluso de comunidades en particular. Y una forma que encontró parte del movimiento mapuche para movilizar y movilizarse fue la (re) construcción de las identidades territoriales que, desde su óptica, constituían estructuras sociales y políticas colectivas que no se circunscribían a elementos individuales, como lo eran longko y werken, sino que poseían una connotación histórica, acaso

más sólida, que las vinculaban directamente con los procesos de enmarcamiento sintetizadas en las nociones de Mundo y País Mapuche. Prácticas culturales, uno puede suponer, sedimentadas y presentes en la memoria colectiva de las comunidades y del can en forma fragmentada, y que constituirían un conjunto de saberes que desafiarían no solo el olvido, sino que las distorsiones de la historia oficial chilena que ha barbarizado e invisibilizado al mapuche. No se trata, por supuesto, de la saturación de recuerdos que puedan conducir a ciertos "abusos de la memoria" y que, como Funes el memorioso de Borges, puede etetalles $y$ de los detalles hasta el punto de faltar el tiempo humano y, acaso también el divino, para recuperar el pasado. Claro, porque

"Funes no solo recordaba cada hoja de cada árbol de cada monte, sino cada una de las veces que la había percibido o imaginado... Sabía las formas de las nubes australes del amanecer del 30 de abril de 1882 y podía compararlas en el recuerdo con las vetas de un libro en pasta española que solo había mirado una vez y con las líneas de la espuma que un remo levantó en el Río Negro la víspera de la acción del Quebracho" (Borges, 1944)

Por otra parte, tampoco se trata de la saturación del olvido que, como en el Macondo de Cien Años de Soledad, devenga en una pérdida generalizada de la memoria que obligaría a colocar papeles con su respectivo nombre a todas las cosas y lugares para no olvidar como se llaman. Solo con el retorno de Melquíades desde la oquedad de la muerte portando un brebaje mágico sería posible poner fin a la peste del olvido. Se trata -uno podría argumentar- simplemente de otorgar la posibilidad a todos los Melquíades de esta tierra, que de una u otra manera también regresaron de la muerte, de contar su propia historia, rehumanizar a los deshumanizados a través de la certificación y acreditación del testimonio como el primer paso hacia la reconstrucción histórica y de este modo, como señalara Benjamin, adueñarse de un recuerdo tal y como relumbra en el instante de un peligro (Benjamín, 1955). Y la memoria mapuche, ahora inserta en un movimiento político y trasformador, parece articular elementos cosmovisionales, cosmogónicos, mnemónicos, territoriales, térreos, étnicos y nacionalitarios. Entonces, la (re) construcción de identidades territoriales puede ser considerada parte constitutiva de dicho proceso y, también, del derecho a la autodeterminación. Es en este contexto que el movimiento autonomista señala:

"cuando se crearon los primeros conflictos fue para crear condiciones para sentarnos con el gobierno de igual a igual. Y la única manera que podíamos lograr esto era a través de la organización y la movilización. La presión social tenía que manifestarse en la práctica y no solo en el discurso y por eso comenzaron las recuperaciones

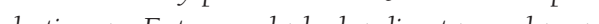
de tierras. Entoncto ción de toda la con la nuestra estrategia. Otro elemento importante es que quienes toman las decisiones y caminos a seguir deben ser las comunidades. También era importante que existiera una relación más estrecha entre las comunidades en todo este proceso. Otro aspecto fundamental es la reestructuración de identidades territoriales mapuche . Finalmente, debemos ser capaces de generar nuestra economía propia, crear una economía mapuche propia (Reiman Alfonso, 2000, entrevista personal)

Así, pareciera que como resultante de los procesos de enmarcamiento y la mapuchización de los mismos, se verificaron otros procesos concomitantes: modificaciones en la forma de relación del movimiento con las comunidades, en el repertorio de acciones que, desde ahora, pasaban a ser del tipo directo y confrontacional y, además, el elemento de economía propia se posicionaba como componente esencial para mantener la independencia del movimiento y reducir las posibilidades de manipulación o cooptación partidaria, estatal o empresarial. Se intentaba, asimismo, posicionar o reposicionar a las autoridades mapuche en un rol central y a las identidades territoriales como espacios de (re) construcción del Mundo y País Mapuche. Después de todo, plantean los mapuche, para el movimiento del movimiento en Lumako el pensarse desde lo mapuche remitía a un pasado común o, al menos, a un pasado hilvanado con retazos de memoria colectiva e individual y ello, en relación a las identidades territoriales, implicaría, acorde a los mapuche, la dificultad de hablar

"de números, de hectáreas, de extensiones, porque eso es lógica occidental, no mapuche... lo que importa es que en cada uno de estos territorios se reconstruya la organización social y política de nuestro pueblo. Las organizaciones de carácter territorial son aquellas que culturalmente el pueblo mapuche ha tenido" (Reiman, Alfonso, 2000, entrevista personal.

Es decir, se articulan dos elementos: uno de carácter mnemónico de índole referencial y otro con carácter de futuro que agenciaría el proceso (re) constructor, acaso aquel juego de espejos donde una sociedad busca mirarse a sí misma y se duda, se sospecha, se interroga, pero no sobre lo por-venir, sino que ian, 2004) No obstante, parece ser aquí precisamente donde se confrontan las dos vertientes principales del Movimiento Mapuche Autonomista: una más culturalista, que apostaría a un proceso reconstructor, con mayor o menor grado de esencialismo y, otra más nacionalitaria, que visualizaría más bien un proceso constructor, conteniendo y preservando componentes valóricos y algunas practicus y estucturas culturales y políticas de su Mundo y su País. En otras palabras, comprender la territorialización de la demanda y accionar mapuche a partir de Lumako es vital para entender al movimiento autonomista pero también para apreciar sus divergencias, tanto conceptuales como de estrategia política. Para la Coordinadora Arauko-Malleko, las comunidades rurales deben constituir el foco de la lucha $y$ todos los esfuerzos deben estar dirigidos a potenciar dichos territorios y ello es congruente con la afirmación de que el proyecto de liberación ha sido elaborado desde abajo, desde las comunidades y por eso se sustenta y se proyecta, porque son la comunidades las que más han sufrido la política de exterminio del Estado chileno (CAM, Op. Cit.). Se $\mathrm{da}$, dicen los mapuche,

"la negación de nuestros derechos fundamentales, que son el acceso a los espacios ancestrales propios para dar continuidad a nuestro proyecto de pueblo, como era, como debió haber sido. Es la mirada como CAM, como proyecto politico, ideológico, en la medida que nosotros perdemos el territorio se descompone todo un proceso de búsqueda, se desestructura todo. Desde ahí está el quiebre, incluso desde una mirada cosmovisionario cosmogonario del pueblo mapuche. Si tu no tienes la territorialidad, los espacios muy especificos dentro de una concepción de mundo mapuche, incluso dejas de ser, y al perder la esencia o el Ser mapuche, no se puede levantar un proyecto propiamente mapuche que es lo que queremos levantar nosotros" (Llaitul, 2011).

La conclusión parece ser que es solo en aquellos espacios donde los mapuche se pueden reconstruir efectivamente como pueblo. Por su parte, para la Identidad Territorial Lafkenche, el espacio territorial en el cual operan y donde pretenden (re) constituirse como Identidad Territorial en la provincia de Arauco es más acotado, específicamente circunscrito a los autodefinidos Espacios Territoriales Mapuche de Patrimonio Lafkenche (Identidad Ma- 
puche Lafkenche, 1999) que son siete, situados en al menos seis comunas de la mencionada provincia. A ello hay que agregar, por cierto, la costa, que, señalan los lafkenche, les pertenece, ya que comprende la relación sagrada y espiritual que con ella e mantiene desde tiempos inmemoriales (Ibídem, 1999). En lo concerniente a la Identidad Territorial Nagche, se plantea también la reconstrucción del Territorio, impulsar la creación de la institucionalidad mapuche, la educación, la economía el deporte, concretamente el palin ${ }^{17}$, y la defensa de los recursos naturales y, particularmente, el derecho y defensa del agua (Convocatoria a Tercera Asamblea Naghe, 2005). En términos estratégicos movimentales, pareciera adherirse a la idea que indicaría "que las organizaciones de carácter nacional no tienen futuro, nunca han funcionado com instrumento eficiente para nuestras comunidades (Reiman, Alfonso, 2000, entrevista personal). Lo anterior se contrapone directamente con aquellos que sostienen que la fragmentación de las identidades solo contribuiría a la fragmentación política, a la división y al debilita mapuche tendra potencil emancipador. $Y$ un mapuche tendría potencial emancipador. Y un clave para comprender dicha postura radica en la diferenciación entre identidad étnica e identidad nacional, pues -señalan algunos dirigentes- si bien es cierto que:

"la existencia étnica mapuche podria, bajo ciertas condiciones siempre limitadas, mantenerse transitoriamente en cualquier lugar, la existencia nacional mapuche sólo es posible «conquistando un país». Más claro aún, en los escenarios politicos y económicos que hoy presenta mundo, en la medida que una etnia no bogra la existencia nacional, está condenada a desaparecer como tal
(Naguil, 2005).

Por lo tanto, para el movimiento la dimensión territorial pasa a ser fundamental, mas no frag mentada en pequeñas identidades territoriales, sino que conformado como país o (re) construido como Wallmapu o País Mapuche. En este sentido,

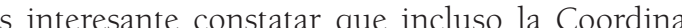
dora Arauko Malleko, que centra su accionar en las comunidades como una forma concreta de territorialización de su lucha, se plantea explícitamente la reconstrucción como nación mapuche y la liberación nacional en el contexto de lo que se percibe como la ocupación militar de su territorio por un país extranjero como lo sería Chile. En otras pala- bras, también se vislumbra como objetivo político la creación, generación o reconstrucción del Wallmapu. Evidentemente, no es lo mismo construir que reconstruir, pero lo importante parece ser que al verse amenazada la identidad mapuche también se ve amenaza construcción de una concepción del mundo. Y esta cosmovisión no se relaciona solamente con metarrelatos o un mito fundador, sino que remite también a los seres concretos, a sus vivencias, a su cotidianidad. En cualquier caso, se hurga en la memoria para proyectarse al futuro, asumiéndose que el pueblo mapuche tiene sus orígenes, su cultura, su historia, su Mundo y su Pás, y, por lo mismo, el Movimiento Mapuche Autonomista parece haber intentado enfrentar esto con recurso a lo identitario, a la (re) construcción del Mundo Mapuche y del País Mapuche. Por lo tanto, si bien es cierto que por una parte se busca el fortalecimiento de una identidad étnica, por otra, se busca también la vigoración nacionalitaria en la perspectiva de la construcción de una nación, aunque no exista claridad meridiana de lo que esto conllevaría. Entonces se elaboran símbolos y ritos que cohesionan, socializan y fortalecen el sentido de pertenencia, lo cual sería vital para un pueblo como el mapuche cuya cultura y sociedad han sido violentamente intervenidos en búsqueda, como se argumenta desde el movimiento, de su desestructuración. En este sentido, parece existir consenso al interior del Movimiento Mapuche Autonomista -con distintos grados de énfasis- en que el pueblo mapuche se encuentra dramáticamente desestructurado, puesto que, como señalan, le han arrebatado quebradas, montes, arroyos, bosques y, por lo mismo, el proceso (re)constructor pasa necesariamente por la recuperación de aquellos espacios ancestrales, ya que de ese modo, sostienen,

"nuestra espiritualidad tendría más capacidad de expresión, por eso al recuperar tierras que nos pertenecen y ejercer control territorial, la gente le encuentra más sentido a la vida, los ancianos le encuentran más sentido a la rogativa, y el conocimiento está entre esos mismos viejitos. Ellos saben cómo hacer la casa, cómo plantar, cómo hablar el mapudungun. Hay mayor respeto entre nosotros, una mejor calidad de vida y un respeto por nosotros, una mejor calidad de vida y un respeto por claro que el hombre no es el centro del mundo, sino que solo uno más, como una planta, un árbol, un río. Son todos elementos identitarios importantes en el proceso de reconstrucción y del proceso de acumulación de fuer- zas para construir la nación mapuche" (CAM, citado en Tricot, 2006: 312 y 313)

El problema, por cierto, es que el Wallmapu fue invadido por el Estado chileno y la apropiación no fue solo territorial fue solo territorial, sino que cultural, social, económica y militar, y ello continúa siendo así hasta la actualidad. De hecho, la legislación indígena elaborada como consecuencia del Pacto de Imperial establece que las culturas indígenas forman parte del patrimonio de la nación chilena. Es decir, se argumenta desde el movimiento, "es el Estado chileno el que decide por nuestras tierras, que se cree dueño del pueblo mapuche y por eso en los discursos hablan de 'nuestros' pueblos originarios, o 'nuestras' comunidades" (Vilches, 2010, entrevista personal). Esa creencia de propiedad absoluta sobre otro pueblo la reflejan en su accionar, reiteran, "es decir son ellos los que le dan la entrada a las mineras, a las forestales, a las empresas energéticas sin importarles nuestra opinión" (ibídem). Debido a lo anterior es que el movimiento mapuche mantiene que se ha materializado una asimilación y destrucción cultural codificada en leyes y que es síntesis de una línea de pensamiento supuestamente redentora del indígena que hiciera exclamar a un historiador como Eyzaguirre que "cuando el indio americano, rescatado de la obscuridad de sus ídolos, conoció al Dios del amor y se dirigió a Él con las voces tiernas y confiadas del Padrenuestro, no lo hizo ni en francés ni en italiano, sino en la viril lengua de Castilla" (Eyzaguirre, 1947:30). Dicho etnocentrismo, uno podría argumentar, nutre el racismo y la discriminación y, en el caso concreto del movimiento mapuche, alimenta su satanización y refuerza su negación. Entonces el mapuche se refugia en su historia, su cultura, identidad, memoria y territorio, ora como pueblo-nación, ora como Identidad Territorial específica. Por lo tanto, como se ha indicado, el surgimiento del Movimiento Mapuche Autonomista respondería no solo a la necesidad de resolver un conflicto existente en términos políticos, culturales o económicos, sino que también de pervivencia. Aunque dicha supervivencia pasaría por (re)construirse como pueblo y, por ende, in- cluye sus estructuras antiguas, orientadas por los elementos configuradores del Mundo Mapuche expresados materialmente en los elementos que componen del País Mapuche.

El mencionado proceso, que remitiría a la décad del noventa y que halla su punto de inflexión en umako, no está, como se ha manifestado, exento de contradicciones y dificultades, no es un proceso lineal, sino más bien anfractuoso, donde se enfrentan permanentemente las posiciones más culturalistas y aquellas de índole más nacionalitaria, aunque ambas claramente políticas y orientadas or la demanda autonómica. concreta de las sinuosidades del proceso, del ro del movimiento y la relación de este con el pueblo mapuche, la constituye la relación entre los dirigentes y las autoridades mapuche, más precisamente, los longko. Pareciera que, en algunos casos y en algunos territorios, algunos longko se sintieron utilizados por el movimiento y pronto percibieron que su rol era más bien decorativo y que no poseían mayor protagonismo en las estructuras o proceso de toma de decisiones ${ }^{18}$. Es decir, la dirigencia política del movimiento elaboraba discursos, decidí acciones y políticas de alianzas, por ejemplo, donde los longko poco o nada podían opinar, aunque se hablara a nombre de ellos. Es en este marco que muchas autoridades se fueron restando de la lucha, aunque -en rigor- surgieron otros longko en otros territorios que se incorporaron también a nuevas organizaciones instrumentales o tradicionales como, por ejemplo, la Alianza Territorial Mapuche $^{19}$, el Parlamento Autónomo de Malleko ${ }^{20}$ el Parlamento de Koz-Koz ${ }^{21}$ o la Comunidad Autónoma de Temucuicui ${ }^{22}$. Víctor Queipul, longko de este último sector, ha declarado provenir de una comunidad

"donde los hombres, los weichafe ${ }^{23}$, los kona ${ }^{24}$, los weupife ${ }^{25}$, alzan la voz convencidos de su lucha, aunque el gobierno no reconoce a las autoridades tradicionales mapuche. Pero a pesar de esa negación, nosotros nos identificamos como una estructura, como una estructura cultural que tenemos" (Queipul, 2010, entrevista personal).

18 Señalado en varias entrevistas, pero siempre con la petición de 'permanecer anónima la fuente.

19 Organización surgida el año 2009 y que aglutina a un centenar de comunidades de distintos territorios.

20 Organización que reúne a diferentes comunidades, autoridades mapuche y mapuche, surgida en el ûltimo tiempo

21 Emergió en el marco de la conmemoración del Parlamento original de Koz-Koz, en 2006.

22 Es una de las organizaciones de la comunidad de Temucuicui en la zona de Ercilla.

23 Guerrero mapuche.

24 Joven mapuche caracterizado por su valentía.

25 Orador 
Tan solo un año después, una carta dirigida al presidente Sebastián Piñera por el Parlamento Autónom de Malleko, es rubricada por dos longko (Comunidad Autónoma Temucuicui y Comunidad Cacique José Guiñón); una machi (Lof Cacique José Guiñón) y dos weren (Comunidad Autónoma Temucuicui Lof Ranquilco). Asimismo con ocasión del asesinato del joven comunero Alex Lemun ${ }^{26}$, un conjunt de organizaciones y comunidades mapuche emitio su Kiñe Mapuche Rakizuam ${ }^{27}$ donde señalaba, entre otros puntos, que

"decisiones particulares de determinadas organizaciones no pueden adoptarse por sobre el conjunto que somos los mapuche, más cuando estas tienen que ver con nuestros destinos politicos y el desarrollo a futuro. Ante cualquier interés pequeño están los intereses de pueblo" (Kiñe Mapuche Rakizuam, 2002).

Reiterando la necesidad de establecer mecanismos de consulta permanentes, más específicamente un Trawun ${ }^{28}$,

"para informarnos, consultarnos y adoptar decisiones de conjunto como los antiguos consejos de longko lo hicieron guián es por losincipios de un kimche y de un norche. Estos espacios propios del pueblo mapuch nos deben permitir proponer escenarios para nuestro desarrollo, evitando los conflictos, pero también nos deben dar la medida de nuestra movilización cuando sea necesario" (Ibidem, 2002).

Lo anterior pareciera relevar al menos tres problemas a los cuales se enfrenta recursivamente el movimiento mapuche: la relación entre organizaciones particulares y el movimiento en su conjunto; la relación entre dirigentes funcionales y autoridades mapuche y, finalmente, la tensión constante entre estructuras sociales, culturales y políticas antiguas y aquellas nuevas y claramente occidentales. De hecho, en el caso concreto de Lumako, fue una organización funcional y no cultural mapuche que desen ren un punto de inflexión del Movimiento Aun en un punto de inlexion de hoviniento Autonomista. La Asociación Nankucheo fue creada en el marco de la Ley Indígena de 1993 que obligaba a los mapuche a aglutinarse en dichas organizaciones para convertirse en interlocutores válidos ante el Estado ${ }^{29}$ y, por lo mismo, no constituye una estructura o forma organizativa

propia de los mapuche. No obstante, es posible argumentar que, en un momento determinado, puede haber jugado un rol acaso más, o al menos igual, de relevante que estructuras mapuche o autoridades mapuche del territorio Nagche, entendiéndose, en todo caso, que fueron las las comunidades los actores centrales en los eventos de Lumako. Por otro lado, en términos de organizaciones mapuche que uno podría suponer que remiten más al pasado, ya se hallaban esparcidos los gérmenes de la Coordinadora de Comunidades en Conflicto que, posteriormente, darían origen a la Coordinadora Arauko-Malleko, de suma importancia para la constitución y por cierto José Huenchunao, uno de los principales dirigentes de ambas instancias señalaba que era posible hab de un antes y un después de Lumako, ya que

"hoy el tema mapuche está de alguna manera considerado en el debate nacional. Los actuales usurpadores de nuestras tierras están preocupados. Reconocen que existe un problema de carácter territorial en la zona donde se encuentran nuestras comunidades. Han dicho que el Estado es responsable de buscar mecanismos para resolver estos graves problemas. Al interior de algunas de nuestras comunidades se ha tomado mayor consciencia sobre nuestros derechos. No tan solo por una cuestión cconómica: ademís se comprende que hay que cuestidn ecore nicas a due rales para continuar existiendo (Huenchunao, citado en rales para continuar
Buendía, 1998:12).

En otras palabras, se observa un claro desplazamiento de una demanda economicista o culturalista a una de índole política, sintetizada en la demanda autonómica y que debe, según los mapuche, "reconocer nuestra unidad histórica, nuestras identidades territoriales, nuestras particularidades como religión, lengua, cultura, recursos. Cualquier actitud o afirmación contraria seguirá siendo una forma abierta de racismo, moral y socialmente condenable para una sociedad que busca establecer la justicia y la paz" (ibídem: 12). En cualquier caso, como se ha señalado, existe, desde antes de Lumako, una tensión irresoluta entre las posturas reconstructuras y las constructuras del Mundo y País Mapuche, lo cual implica que el pensarse como mapuche desde lo mapuche o, si se quiere, el proceso de mapuchización de los marcos analíticos del movimiento,

\footnotetext{
26 Alex Lemun, joven mapuche de 17 años asesinado por un balazo policial en la zona de Ercilla en noviembre del 2002.

27 Manifiesto Mapuch

28 Encuentro mapuch

29 Los articulos 36 y 37 de la Ley Indigena establecen las normas para el establecimiento de las Asociaciones Indigenas como organismos
} funcionales que no pueden arrogarse la representación de las comunidades. constituyen complejos fenómenos procesuales que, por lo mismo, adolecen de una cierta opacidad. Dicha tensión, iteramos, también se manifiesta en los roles adscritos a los longko y a los dirigentes del movimiento. Una manifestación particularmente compleja de dicha tensión se materializó en el Parlamento de Koz-Koz. En enero de 2007 millares de mapuche se autoconvocaron en las cercanías res de mapuche se autoconvocaron en las cercanías
de Panguipulli $i^{30}$ para conmemorar el centenario del Parlamento de Koz-Koz realizado el 18 de enero de 1907 en aquel valle ${ }^{31}$. Jorge Weke, werken del encuentro, expresó que "puede haber muchas lecturas de lo que ha pasado todo este tiempo, pero natie discute la denegación de nuestros derechos políticos, culturales, sociales y económicos" (Weke, 2007). Por lo mismo, la convocatoria a este evento planteaba que Koz-Koz no solo tiene que ver con el pasado, sino que, sobre todo, con el presente y el futuro. De ahí que "el mejor modo de conmemoración es levantar propuestas articuladas con miras a recuperar el territorio que nuestros abuelos defendían (Convocatoria a Parlamento de Koz, Koz, 2006), por eso

"desde ya, estamos abriendo nuevos horizontes, haciendo futuro, sentando las bases para ejercer jurisprudencia, lo cual significa que el Estado debe readecuar su relación con el pueblo mapuche, porque hemos dependido del Estado Chileno con graves consecuencias hacia nosotros y en contra de nuestra voluntad. No podemos continuar por más tiempo así. Planteamos además bases sostenibles de alianzas con la sociedad civil y sus movimientos sociales" (Ibídem)

Es este el contexto general en que autoridades mapuche realizaron un llamado a congregarse y dar forma a un encuentro cultural, religioso y político para reconstruirse como pueblo-nación mapuche y elaborar propuestas unitarias que apuntarían hacia la autodeterminación. De hecho, las autoridades convocantes pidieron llegar a este espacio "con la mente y el corazón limpio y abierto" para debatir los primeros dos días solo como pueblo mapuche y los últimos dos con la sociedad civil organiza dicho espacio -hoy perteneciente a un particular y a quien hubo de solicitar autorización para congregarse en el predio- se constataron tres fenómenos entrelazados que, pienso, atraviesan los marcos interpretativos, el repertorio de acciones y las estructuras de movilización del Movimiento Mapuche Autonomista. Por sobre todo, exteriorizan y hacen patente la permanente tensión entre las distintas vertientes principales del movimiento, aunque en la convocatoria se haya realizado un prístino llamado a la unidad del movimiento, indicando:

"la autoconvocatoria mapunche a este encuentro es para aquellos territorios y organizaciones que revindican los derechos colectivos y compartan la necesidad de constituir un Parlamento mapuche (Koyagtun), as como implementar y articular estrategias y acciones corto, mediano y a largo plazo que nos permitan avanzar de manera coordinada, resguardando la autonomía del proceso, tanto en planteamiento como en gestión de pueblo" (Convocatoria a Parlamento de Koz, Koz, 2006)

Llamado internalizado por varios de los participantes al Parlamento quienes se sentían:

"parte de un proceso comprometido con la integración del movimiento mapuche, por lo tanto esto es un gesto de unidad, porque es necesario cultivar la unidad, y en ese sentido, aqui ha habido tiempo suficiente para conversar, establecer confianzas, mirarnos los rostros, avanzar" (Millabur 2007, entrevista personal). Asimismo, el longko Francisco Wichaman convoco co

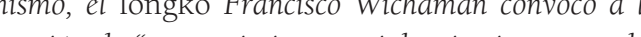
pucion de "un mover partidos políticos y la religión dividen, son parte de problema y no de la solución. No repitamos la misma historia, creemos una nueva historia" (Wichaman, 2007).

Por lo mismo, para algunos asistentes mapuche, el Parlamento fue:

"muy importante para nuestro pueblo-nación, ya que nos posibilita retomar una instancia que nuestros abuelos usaban para tomar decisiones en conjunto. Este es un gran y necesario paso para nuestro pueblo, para comenzar a plantear a toda nuestra gente que no no conformamos con hacer propuestas y esperar que el Estado las apruebe, porque nosotros podemos tomar nuestras propias decisiones. Además, tenemos que ser capaces, en conjunto con la gente que no es de nuestro pueblo, de cambiar la institucionalidad del Estado para ser reconocidos como pueblo nación, tener autodeterminación y que sean respetadas y valoradas nuestras costumbres basadas en una cosmovisión propia" (Caquilpan Rayen, 2007, entrevista personal)

A pesar de lo anterior, lo cierto es que el proceso de reconstitución del Koyagtun lleva implícito en su ADN, uno podría plantear, una contradicción con formas nuevas de organización, más allá de in-

30 Ciudad ubicada en la región de Los Ríos en el sur de Chile, territorio mapuche.

31 Para una versión detallada de dicho Parlamento, ver, por ejemplo (Diaz, 2005; Buendia, 2007). 
tencionalidades unitarias, por ende, la colisión de prácticas y estructuras ancestrales con aquellas de carácter funcional era acaso ineluctable; tanto as que se podría argüir que, en el contexto de la conmemoración de Koz-Koz se produce una especie de otras autoridades ancestraes, que se apropian de este espacio y lo transforma en vehículo de una reafirmación cultural profunda, desplazando desde su vórtice original a la política y a los dirigentes políticos del movimiento. Acorde a lo señalado en el propio Koz-Koz,

"el Koyagtun dispone de dos componentes fundamentales en la toma de decisiones, una dimensión de estructura espiritual y una dimensión de estructura fisica; para eso la regulación armónica la entregan nuestras autoridades politicas y filosóficas por medio de la sabiduría que poseen, con el fin de conducir y proteger integramente la existencia del universo y de la sociedal" (Comision organizadora, Parlamento de Koz-Koz, 2006),

Las autoridades ancestrales desempeñan el rol pivotal en esta instancia que articula elementos cosmovisionales, históricos, mnemónicos y políticos, no solo en territorio williche, sino que en todo el Wallmapu. Entonces, para los convocantes "es un proceso organizativo propio, guiado por nuestras autoridades originarias, planteado con fuerza y convicción desde nuestra espiritualidad y con la participación de distintas organizaciones y comunidades del territorio de Panguipulli" (Ibídem). Parecen haber sido precisamente estas fuerzas espirituales las que se expresaron con vigor entre e vuelo de los queltehues y el tremolar de las banderas enclavadas en el lugar sagrado de Koz-Koz. Para algunos, fue más un Nguillatun que un Parlamento o tal vez un Trawun (Cabral, 2007, entrevista personal), aunque, inequívocamente, dicen, "parte de un proceso de recuperación de todos los espacios simbólicos mapuche" (Weke, 2007, entrevista personal). Acaso, una singular expresión de culturalización de la política donde la presencia de longko, werken, machi y kona se articuló con la memoria antigua para la restauración momentánea de Mapuche. Y, si bien es cierto que se sostuvo con an terioridad a la celebracion del Parlamento que un de los objetivos era "la reconstrucción de nuestro

del autor.

33 Conocimiento educativ

34 Otra forma de decir mapuch

35 Autoridad filosófica mapuche.

36 Conocedor/a de las propiedad de las plantas.

48 pueblo desde la diferencia, siendo conscientes de la diversidad de planteamientos, de disputas y conflictos al interior del propio movimiento" (Invitación a participación en Parlamento de Koz.Koz, 2006) y, además, que se avanzaría "en el planteamiento de acciones concretas y estratégicas en materia de históricas, organi-

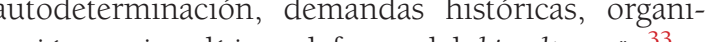
zación sociopolítica, defensa del kimeltunwün ${ }^{33}$ y

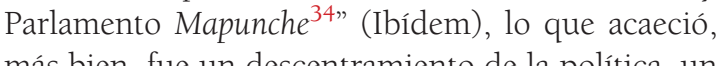
más bien, fue un descentramiento de la política, un reposicionamiento de la cultura, una etnicización de la identidad y un resurgimiento de prácticas y estructuras culturales ancestrales, las cuales, al menos temporalmente, reposicionó a los longko no solo como figuras simbólicas del movimiento -algo que, como se ha planteado, en algún momento puede haber sucedido- sino como eje rector, aglutinador y dirigente. Lo anterior no significa que la política haya estado ausente del encuentro, por el contrario, solo quiere decir que estuvo presente de una manera distinta. De hecho, el análisis de las conclusiones del Parlamento nos hace deducir que la mayoría de los objetivos estratégicos y demandas contenidas en el documento final son preeminentemente políticas: recuperación del territorio mapuche usurpado; generación de estrategias de reconstrucción territorial entre GuluMapu y PuelMapu; reconstruir el Pueblo-Nación Mapuche; consolidar una asamblea constituyente que agrupe a los Pueblos Indígenas para la modificación de la Constitución Política de Chile y que la nueva carta defina al país como Estado Plurinacional; presionar al Estado para ratificar el convenio 169 de la OIT; fortalecer y desarrollar la elaboración de una constitución Mapuche y, además, institucionalizar el Koyagtun mapuche, entre otras (Conclusiones Parlamento de Koz-Koz, 2007). Sin embargo, también se constatan propuestas y acciones dirigidas específicamente a reconstruir o fortalecer prácticas y estructuras propiamente mapuche; es decir, reivindicar el Kimün mapuche y sus formas de reproducción; vigorizar a las autoridades tradicionales y, más precisamente, revitalizar la estructura política y social del pueblo mapuche (Longko, Pijan Kuse ${ }^{35}$, Gnenpin, Machi, Lawentuche$\mathrm{fe}^{36}$, Werken y Kona), así como también impulsar la creación de un ordenamiento tradicional mapu- che como estrategia de defensa y recuperación del territorio (Ibídem). Por lo tanto, más allá de las tensiones verificadas entre las posturas más culturalistas y aquellas más nacionalitarias, en Koz-Koz, una década después de Lumako, se constituyó un espacio de afirmación identitaria, cultural y política que interpeló tanto a la negación originaria como a la segunda negación, sintetizando en sus demanda y propuestas las ideas de Mundo y País Mapuche. En cuanto a la segunda negación, agenciada por la imposición del modelo neoliberal, el Parlamento explícitamente llama a

"detener megaproyectos en territorio mapuche: Aeropuerto, Celulosa, Centrales hidroeléctricas, forestales. y consolidar un desarrollo económico mapuche basado en el respecto al medioambiente y en la acción colectiva, a través de la creación de cooperativas. Con énfasis en el desarrollo de cultivos orgánicos tradicionales y etnoturismo" (Ibídem).

Es decir, al mapuche parece asistirle la certeza de que solo están planteando sus "derechos sociales, lo que nos corresponde como seres humanos en un sistema donde estamos al margen, porque los mapuche tenemos los peores índices en educación y salud, y las empresas forestales, del agua y mineras están destruyendo la naturaleza y afectando a comunidades indígenas que son fracturadas, eliminadas, desplazadas" (Millabur, 2007, entrevista personal). Quizás por lo mismo, por sentirse objeto permanente de discriminación y fracturación por parte de la sociedad dominante, es que en KozKoz se produjo una singular y clara expresión de reafirmación cultural que marginó a la sociedad civil chilena presente ${ }^{37}$. El mapuche dejó de ser el otro, asumió su mismidad y convirtió al chileno en el otro; y esa otredad fue marginada y excluida de los eventos principales del Parlamento, a pesar de haber sido especialmente invitados por la comisión organizadora, mapuchidad cubrió con su refortalecido manto identitario a la estupefacta chilenidad y los Kona ejercieron soberanía territorial, incluso mediante la violencia simbólica. Todo ello bricado con la ceremonia de clausura del Koyagtun realizada por el nguempin Efraín Cheuquefilo en mapudungun que, uno podría suponer, representó la impronta de Koz-Koz, tal vez de mejor modo que la misma lectura de las conclusiones realizadas por Olga Kuripan, descendiente de Francisco Kuripan, uno de los longko participantes del Parlamento original en 1907. En síntesis, las autoridades ancesrales tuvieron la última palabra con el longko Pedro Punoy, de Cayumapu, quien simplemente dijo: Marichiweu, diez veces venceremos.

\section{Mundo Mapuche y País Mapuche}

\section{en clave movimental}

La implosión en el Movimiento Mapuche Autonomista y de la cual Koz-Koz es tan solo una manifestación presupone también la necesaria conceptualización y estructuración como instrumento político movilizador de las ideas y praxis de Mundo y País Mapuche. aunque en un comienzo ello no hubiese estado claramente manifestado en un todo integral, sino que, más bien, se expresó en una serie de elementos políticos, culturales e identitarios disgregados. Sin embargo, con el tiempo se arribó a una elaboración mucho más sistemática que, es posible argumentar, constituye la manifestación de una consolidación de los marcos analíticos mapuche. Ejemplo de lo anteriormente señalado es la propuesta de más de cha de organizaciones mapuche red tada luego de un Trawun ${ }^{38}$ realizado en Quepe en $2006^{39}$ y que diera nacimiento a la Coordinadora de Organizaciones Mapuche- $\mathrm{COM}^{40}$. Es decir, hay definiciones basales desde donde parecen derivar todas las otras demandas que comienzan a perfilarse más claramente en Lumako y que constituyen el núcleo del Movimiento Mapuche Autonomista. en los marcos del novimiento y, particularmente en las nociones de Mundo Mapuche y País Mapuche, mucho de lo cual se halla contenido en la propuesta de Quepe, considerando, por cierto que dos importantes organizaciones se marginaron de la génesis de dicho análisis y propuesta. El manifiesto de Quepe está estructurado en torno a tres Pes fundamentales: Reconocimiento de Derechos Políticos y la Libre Determinación; Participación Política; Tierras y Control Territorial (Propuesta de Organizaciones Mapuche, 2006). Y cuatro ejes complementarios expresados en el concepto mapuche de Küme Mongen ${ }^{41}$ : Economía, Educación, 
Salud, Legislación y justicia (Ibídem). No obstante, quizás más significativo aún desde la óptica de la mapuchización de los marcos interpretativos, sea la reivindicación por los mapuche del Wallmapu como "un eje central de nuestras demandas y de las reclacorque son los pilares fundamentales de nuestra existencia
(Ibídem)". Además, señalan,

"para el Pueblo Mapuche, los conceptos de Wallmapu y de Ixofil Mongen ${ }^{42}$ configuran nuestro territorio, sobre la base de los elementos materiales e inmateriales. Los elementos materiales son las tierras, el espacio fisico donde habitan los pueblos indigenas $y$ todos los recursos que hay en ellas. Los elementos inmateriales son patrimonio cultural e intelectual, las leyes, costumbres, sistemas de tenencia, sistemas de creencias, formas de organización e instituciones. En sintesis, Territorio Mapuche involucra que las comunidades poseen las tierras los recursos natur les del espacio en donde hablin e influyen y desarrollan autogestión politica, económica, influyen y desarrollan autogestión politica, ecorict
social y cultural de dicho espacio." (Ibídem).

Se entiende, entonces, por Mundo Mapuche y País Mapuche, aquello que,

"desde nuestra cosmovisión, nuestros antepasados desde sus origenes construyeron paulatinamente un modo particular de convivencia y de relación con todos y cada uno de los componentes del Wallmapu o del Mapuche Wajontu Mapu, donde el universo y el cosmos, han establecido un ordenamiento universal a lo que nosotros Ilamamos Nor-Felen ${ }^{43} y$ que entendemos como la ley naturato

natural o autorregulación de la naturaleza" (Ibíd."."

El movimiento, por lo tanto, parece transitar entre la reconstrucción y la construcción del Mundo y País Mapuche o, para ser más precisos, y considerando la heterogeneidad del movimiento, habría que plantear que la demanda y propuesta del movimiento apunta hacia la (re) construcción del Mundo y Pais Mapuche. Ello trasciende Lunah ko o Quepe, toda vez que incluso la Coordinadora Arauko-Malleko, surgida después de Lumako y auto-excluida de Quepe ha sostenido que el Mundo Mapuche está desestructurado y, por ende, debe acometerse un proceso de reconstrucción liberador.

Sea como fuere, lo que parece evidente es que la deflagración en Lumako, con sus narrativas alterna-

2 Todo el Sistema de Vida en mapudungu.

43 Ley de autoregulación de la naturaleza.

44 Al hablar de militarización nos referimos a la permanente presencia y accionar policial en las comunidades, más que a la presencia del ejército.

45 Por la vía legal, la comunidad mapuche Pablo Quintriqueo Huenuman de Cuyinco, recuperó, luego de un litigio que se prolongó por cerca de 18 años, 1.650 hectáreas de un total de 12.000 que comprendian originalmente el territorio que habitaban. tivas de Mundo y de País, así como un repertorio de acciones que incluía la recuperación de predios, la autodefensa, el control territorial y, por lo tanto, el enfrentamiento directo con las fuerzas policiales, alcanzó también al Estado y sociedad chilenas. El movimiento no solo se rearticuló organizativamente, sino que también discursivamente, y ahora los conceptos de territorio y libredeterminación, que no habían sido importantes en la década de los ochenta o comienzos de los noventa, pasaron a ser predominantes (Aylwin, 2009, entrevista personal). Entonces el Estado respondió con la violencia, inicialmente mediante el recurso a la aplicación inmediata de la Ley de Seguridad Interior del Estado y la militarización ${ }^{44}$ de las comunidades en conflicto y luego mediante la aplicación de la Ley antiterrorista. El objetivo era desarticular al Movimiento Mapuche Autonomista.

Quizás, porque tanto para el gobierno como para los empresarios forestales, los mapuche que reivindicaban tierras como suyas constituían "una mafia que actúa con balazos y hachazos contra personal de las empresas y contra carabineros" (Letamendi, citado en Tricot, 2006, pág. 202), Andrés Ovalle, gerente regional de Mininco, declaró que "pase lo que pase, la empresa no claudicará en sus derechos de explotar los bosques que le pertenecen" (Ovalle, citado en Buendía, 1999: 4-5). Bosques que los mapuche consideran ancestralmente suyos, porque antes, manifiestan, "todo era nativo, había agua, yerbas, árboles y arbustos para las enfermedades. Ahora no hay nada, se lo llevaron todo. Cada vez es más difícil hacer remedios y sanar enfermos, hay que ir a otros lugares a buscar yerbas" (Ancamilla, 1999, entrevista personal). Incluso en los pocos casos en que los tribunales han fallado a favor de una comunidad mapuche, como en Cuyinco ${ }^{45}$, en la comuna de Los Álamos, la depredación forestal continúa inalterable. Es más, acorde a comuneros de Cuyinco, a partir del año 1997, es decir, en un proceso concomitante al de Lumako,

"la situación se ha hecho más difícil para nosotros, la Forestal no ha cumplido la orden judicial y Bosques Arauco ha convertido Cuyinco en un campo militar. Aqui hay módulos de vigilancia con contingente de 15 guardias, ex miembros de las fuerzas armadas, que recorren el fundo 24 horas al día. Es nuestra tierra, pero ellos actúan como si fueran los verdaderos dueños, acosándonos permanentemente. Se trabaja la alta inteligencia, con los guardias de seguridad y también la Dipolcar-Dirección de Inteligencia Policial de Carabineros- casetas de vigit agresiones, golpizas, provocaciones de todo tipo" (Fren Fernando, 2001, entrevista personal).

Una de las consecuencias de esta política de criminalización impulsada desde el Estado frente a la protesta social mapuche por la imposición de inversiones o los impactos ambientales y culturales que estas provocan en sus comunidades, a la exclusión política y económica, ha sido llevar a la cárcel a decenas de mapuche acusados de cometer actos terroristas (Aylwin, 2009, entrevista personal). Se puede apreciar aquí una lógica histórica de represión que transciende momentos o períodos concretos, cambiando solo su forma. En el siglo XIX ya se señalaba que "consquista no quiere decir bajo ningún concepto exterminio; i que bien puede subyugarse a los indijenas sin matarlos" (Vicuña Mackenna, 1868:16). Es decir, no se cuestionaba la conquista de otro territorio u otro pueblo, sino que se aconsejaba, en lo posible, no exterminarlo. En la actualidad tampoco se cuestiona el derecho a la conquista por parte del Estado; tampoco parece cuestionarse el derecho a subyugar a los mapuche e, incluso, a matarlos, como ha sucedido recientemente. La criminalización de la protesta social, acorde a los propios mapuche,

"no es algo nuevo para el Mundo Mapuche, siempre se han criminalizado las reivindicaciones de los pueblos indigenas. Ya a mediados del siglo XX, bajo la figira del cuatrerismo, se hacian los allanamientos a las reducciones indigenas y sencillamente se ejecuta extrajudicialmente a comuneros acusados de "cuatrerismo", aunque en definitiva eran comuneros que tenian conflictos de deslindes de tierras o de recuperaciones de tierras con latifundistas. La represión continuó con la dictadura y no cambió en democracia donde ya el presidente Aylwin procesó a 144 mapuche por asociación ilícita y usurpación de tierra. (Loncon Lautaro, 2010, entrevista personal).

A la represión también se adicionaron esfuerzos sistemáticos por dividir y cooptar a parte del movimiento. Es en este contexto que, en los albores del surgimiento del Movimiento Mapuche Autonomista este último señalaba que antes las maniobras divisionistas del Estado, el movimiento

"no debe dejarse arrastrar ni distraer por esta falsa contradicción alimentada por el gobierno, que se suma a su interpretación de rivalidades de liderazgos al inerior del movimiento mapuche que ha promovido las movilizaciones, en la cual la falsa y burda disputa de "quien es más radicalizado" sería un problema central. Si bien las diferencias de ópticas en el movimiento acción no deberían ser actualmente una contradicción esencial" (Liwen, 1999).

Sin embargo, las políticas asistencialistas y divisionistas del gobierno, junto a la represión constante -selectiva y generalizada a la vez- rindieron fruto en parte, debilitando al movimiento y forzándolo a un estado de dispersión y reflujo, sostienen los mapuche (Cayuqueo, 2009, entrevista personal Curihuentro Claudio, 2009, entrevista personal Quilaqueo, 2009, entrevista personal; Quintrileo 2010, entrevista personal). Las movilizaciones de fines de la década del noventa y mediados del 2000 han decrecido, aunque quizás es más acertado deci que han modificado su carácter, pues se han territorializado y particularizado en la línea de algunas de las características de los movimientos sociale contemporáneos en América Latina, puesto que sostienen algunos autores, como

"resultado del proceso de concentración del ingreso, la riqueza y los recursos naturales que signa a las politicas neoliberales, nuevos movimientos sociales de base territorial tanto en el mundo rural como también en el espacio urbano han emergido en el escenario latinoamericano, constituyéndose en algunos casos, po ejemplo, en relación a su identidad étnico-cultural (los movimientos indigenas) o en referencia a su carencia (los llamados "movimientos sin", por ejemplo los sin tierra sin techo o sin trabajo) o en relación a su hibitat de vida compartido (por ejemplo los movimientos de pobladores)". (Seoane, Taddei, Algranati, 2006: 232 y 233)

La territorialización de la demanda y del accionar mapuche no constituye un fenómeno actual, sino que se remonta a Lumako, pero se ha transformado más bien en lo que podría denominarse comunidadización del accionar, toda vez que el accionar se ha concentrado en algunas comunidades para sostenerse en el tiempo y, después, trasladarse a otras comunidades, aunque en ello puede no haber algo planificado o coordinado. Sea como fuere, el Estado continúa implementando su política de criminalización del movimiento, aplicando la Ley antiterrorista. Es decir, como expresa el longko Aniceto Norin, "primero nos encarcelaron a nosotros" hora siguen encarcelando a nuestros hermanos, siguen aplicando la ley que nos aplicaron a nosotros. 
así es más fácil condenarlos... pero los poderosos los grandes terratenientes, los particulares, hacen ellos mismos atentados y después culpan a los mapuche para justificar la represión" (Norin, 2009, entrevista personal). $Y$, la verdad, como argumendigamos o hagamos, porque te condenan de antemano. Esto no es jurídico, sino político..." (Pichun Pascual, 2005, entrevista personal). Tal vez por lo mismo, ninguna de las estrategias gubernamentales parece haber resuelto el problema de fondo, pues la demanda mapuche surgida en Lumako es también esencialmente política y por lo tanto, requiere de y no de una judicialización criminalización del tema. Los mapuche están convencidos de que poseen "un derecho histórico, reivindicando y recuperando nuestras tierras ancestrales" (Norin, 2009, entrevista personal), de manera que el Movimiento Mapuche Autonomista remite al territorio y no solo a la tierra, a la identidad y cultura mapuche, a la memoria histórica también al futuro en la forma de un proyecto de País Mapuch construcción, intenta reflejar un Mundo distinto al occidental. Por todo lo anterior, es plausible hablar de un antes y un después de Lumako.

\section{El giro movimental a modo}

\section{de conclusión}

El Movimiento Mapuche Autonomista, aquel surgido en la década de los noventa y simbólicamente datado en Lumako, ha transitado desde reivindicaciones fundamentalmente economicistas y culturalistas hacia demandas de índole Si bien es cierto que no es la primera vez que el movimiento enarbola la reclamación autonomista, pareciera ser que es solamente en los últimos lustros que esta se ha ubicado como componente central del repertorio de demandas y de acciones de las principales organizaciones mapuche. Asimismo, parece plausible señalar que las nociones de Mundo Mapuche Pais Mapuche constituyen la síntesis de la demanda y propuesta de parte significativa del Movimient Mapuche Autonomista. Como se ha argumentado, dicha síntesis emanaría de un sostenido proceso de enmarcamientio agenciado por el movimiento, y que en lo medular apunta hacia una precisión de la situación conflictual entre el pueblo mapuche y el Estado y sociedad chilenas.

La modificación en el contenido de los marcos interpretativos mapuche implicó, como resultante, un análisis sistemático y distinto de la relación mapuche-chilena que redefinió la situación conflictual, precisó las causas de la tensión, puntualizó los actores principales, determinó las estrategias a implementar y, en la práctica, conllevó el diseño e implementación de un repertorio de demandas y movilizar a los mapuche $y$, al mismo tiempo, interpelar al Estado chileno. En lo sustancial, pareciera que el mencionado proceso de enmarcamiento viabilizó la arquitectura de una visión de la realidad que trascendería las fronteras de lo político para adquirir una dimensión estructural, toda vez que la demanda autonomista no solo reflejaría una coyuntura particular, sino que se situaría en un horizonte temporal de carácter histórico y además, daría cuenta de una relación asimétrica permanente. Lo anterior, desde el punto de vista del movimiento autonomista, contrapone a la mapuchidad con la chilenidad, a la cultura mapuche con la cultura chilena, al País Mapuche con el País chileno, al Mundo Mapuche con el Mundo chileno. El movimiento del movimiento en Lumako impulsó la mapuchizacion de sus propios marcos interpretativos como una forma específica de pensarse como mapuche desde lo mapuche

\section{Bibliografía}

BENJAMIN, W. Tesis de Filosofía de la Historia, Revolta Global, http://www.revoltaglobal.net

BORGES, J. L. (1944). Funes el memorioso, en Artificios, Editorial Emecé, Buenos Aires.

BUENDíA, M. (2001). Estrategia de la Coordinador Arauco-Malleco, Revista Punto Final. No 507, Año XXXVI, 12 al 25 de octubre 2001, Santiago, Chile.

BUENDÍA, M. (1999). Nuestro Kosovo fue la "Pacificación de La Araucanía", Revista Punto Final, № 443 , Año XXXIII, 16 al 19 de abril 1999, Santiago, Chile.

IBARRA, P. (2005). Manual de Sociedad Civil y Movimientos Sociales, Editorial Sintesis, España.

IGLESIAS, P. (2007). Enfoques teóricos sobre la acción colectiva: alcance y límites para el estudio de los movimientos globales, Universidad Complutense de Madrid Àgora - Revista de Ciencias Sociales No 17

MARIMAN, J. (2003). Identidad Fragmentada, Periódico mapuche Azkintuwe, Diciembre

MCADAM, D., MCCARTHY, J. y ZALD, M. (1999). Movimientos Sociales: Perspectivas Comparadas, Ediciones Istmo, Madrid.

MOULIAN, T. (2004). De la política letrada a la política analfabeta. La crisis de la política en el Chile actual y el "lavinismo", LOM Ediciones, Santiago, Chile.
NAGUIL, V. (1999). Conflictos en el territorio mapuche: Intereses, derechos y soluciones políticas en juego, en Liwen, Revista del Centro de Estudios y Documentación Mapuche Liwen, №5. Temuco, Chile.

SEOANE, J., TADDEI, E., ALGRANATI, C. (2006). Las nuevas configuraciones de los movimientos populares en América Latina en, Borón, Atilio y Lechini, Gladys, Política y movimientos sociales en un mundo hegemónico. Lecciones desde África, Asia y América Latina, CLACSO. Argentina.

TARROW, S. (2004). El poder en movimiento: Los movimientos sociales, la acción colectiva y la política, Editorial Alianza. España.

TARROW, S. (1992). Mentalities, Political Cultures, and Collective Action Frames, en Morris, Aldon y Mc Clurg Muller, Carol (Eds.) Frontiers in Social Movements Theory, Yale University Press. EE.UU.

TILLY, C. (2002). Stories, Identities, and Political Change, Rowman \& Littlefield. EE.UU

Publishers, Lanham

RICOT, T. (2006). La Lucha del Pueblo Mapuche, Ediciones Ilwen, Santiago, Chile.

TRICOT, T. (2011). La Negaciones de las clases dominantes y el Movimiento mapuche en, Bicentenario[s...] lainoamericanos, № 10 (ler Semestre 2011), LOM Ediciones, Santiago, Chile.

TRICOT, T. (2010). Sociología y Mundo Indígena en Movimiento, Revista Kutral de Sociologia, N 1 , Diciembre, 2010, Universidad Viña del Mar, Chile.

TRICOT, T. (2009). Lumako: punto de inflexión en el desarrollo del nuevo movimiento mapuche, Revista de Historia Actual, Primavera. Cádiz, España.

TRICOT, T. (2009), El nuevo movimiento mapuche: hacia la (re)construccion del mundo y pais mapuche, Polis, Revista Académica, Universidad Bolivariana, No 24 , Diciembre. Chile.

Entrevistas

AYLWIN, J. (2009). abogado, Codirector del Observatorio de Derechos Ciudadanos, Temuco.

ANCAMILLA, M. (1999). Comunidad Pantano.

CANIUQUEO, S. (2010). historiador mapuche, Temuco.

CAQUILPAN, F. (2009). Corporación de Comunicaciones Mapuche Xeg-Xeg, Likan Ray.

CAQUILPAN, R. (2007). Koz-Koz.

CAYUQUEO, P. (2009). Partido Mapuche Wallmapuwen, Temuco.

CURRIAO, A. (1997). entrevista personal.

FREN, F. (2001). comunero, Cuyinco.

HUENCHUNAO, J. (2010). Coordinadora Arauko-Malleko, Angol.
LITUL, H. (2011) Coordinadora Arauko-Malleko, Angol.

LONCON, L. (2010). Consejo de Todas las Tierras, Valparaíso

MARILEO, A. (1998). Gnenpin mapuche, Temuco. MARIMAN, P. (2010). historiador mapuche, Temuco IILLABUR, A. (2007). Identidad Territorial Lafkenche Koz-Koz.

NORIN, A. (2009). Longko Comunidad Didaico.

PAINECURA, J. (2010). Temuco.

PAINEMAL, W. (2009). Partido Mapuche Wallmapuwen, Temuco.

PANCHILLO, M. T. (2009). Escuela de Filosofía, Espiritualidad y Sabiduría ancestral mapuche, Traiguen.

PENCHULEO, L. (2009). Partido Mapuche Wallmapuwen, Puerto Saavedra.

PICHUN, P. (2005). Longko de Temulemu, entrevista per-

QUEIPUL, V. (2010). Longko Comunidad Autónoma de Temucuicui, Valparaíso.

QUILAQUEO, G. (2009). Partido Mapuche Wallmapuwen, Temuco

QUINTRILEO, M. (2010). Parlamento Autónomo de Malleko, Temuco.

REIMAN, A. (2000). Asociación Ñankucheo de Lumako Identidad Territorial Nagche.

REIMAN, G. (2009). Asociación Nankucheo de Lumako, Identidad Territorial Nagche.

VILCHES, M. (2010). Identidad Territorial Lafkenche, Temuco.

WEKE, J. (2007). Parlamento de Koz-Koz, Koz-Koz, Panguipulli.

Documentos

CARTA PÚBLICA DE LAS AUTORIDADES ORIGINACIAS MAPUCHE DEL WALL MAPU, Rewe de Weicha, 2004 .

CONVOCATORIA PARLAMENTO MAPUCHE KOZ KOZ (2006) (Panguipulli) 18 al 21 de enero 2007, mauexpress.

DECLARACION OFICIAL DE NUESTRA RELACION CON LA COORDINADORA ARAUCO MALLECO (2005). Meli Wixan Mapu, Diciembre.

DECLARACIONES EJERCITO ZAPATISTA DE LIBERACION NACIONAL- EZLN. LA HORA DE LA PALABRA LA CONSULTA NACIONAL ES UN LUGAR HABLAR Y ESCUCHAR. 25 de agosto de 1995

DECLARACION, SOBRE LA CONSULTA: PARA TODOS TODO, NADA PARA NOSOTROS. 10 de junio de 1994 - EZLN.

DE LA DEUDA HISTÓRICA NACIONAL AL RECONOCIMIENTO DE NUESTROS DERECHOS TERRITORIALES, Identidad Mapuche Lafkenche de la Provincia de Arauko, VIII región de Chile, 1999. 
DOCUMENTO PRELIMINAR: Resoluciones en torno a territorio y territorialidad; situación sociopolítica y cultura; Kimeltuwün Kozkoz mapu, Walung, Enero Kullen, 2007

PROPUESTA DE ORGANIZACIONES TERRITORIALES MAPUCHE AL ESTADO DE CHILE, Wallmapu, Pegun, 2006

VICUÑA, M. B. La conquista de Arauco. Discurso pronunciado en la Cámara de Diputados, 10 de agosto 1868.

\section{Ciudadanía en contextos de violencia y temor: algunos desafíos para la intervención comunitaria hoy}

Citizenship in contexts of violence and fear:

Some challenges for current community interventions

Gianinna Muñoz A

Docente del Departamento de Trabajo Social de la Universidad Alberto Hurtado. Magister en Trabajo Social por la Pontificia Universidad Católica de Chile. Estudiante del doctorado en Trabajo Social de la Escuela de Estudios Politicos, Universidad de Bristol, Inglaterra. Correo electrónico: Gianinna.Munoz@bristol.ac.uk

Resumen

Este artículo se propone analizar las posibilidades de construir ciudadanía a través de programas sociales orientados a la promoción de seguridad ciudadana en barrios afectados por la violencia y el temor. En este marco, será examinado el "Proyecto de Movilización Comunitaria en la Villa Caro Urzúa", que fue implementado por un equipo profesional del Departamento de Trabajo Social de la Universidad Alberto Hurtado durante los años 2008 y 2009. Tomando este proceso de intervención como referencia, en este artículo se analizan los marcos teóricos y metodológicos desde los que se fundan las intervenciones gubernamentales orientadas a la prevención del delito en Chile. A partir de los resultados de este proyecto de intervención, se plantean algunos desafíos para la promoción del ejercicio ciudadano a través de intervenciones comunitarias en estos contextos.

Palabras clave. Ciudadanía, intervención comunitaria, violencia y temor.

Abstract

This article aims to analyse the possibilities for constructing citizenship through social programmes oriented to promote 'citizen security' in neighbourhoods which are affected by violence an fear. The Project "Movilizacion Comunitaria en la Villa Carol Urzua" will be examined as a reference for further reflection on this topic. This Project was undertaken by a professional team from the School of Social Work of the Alberto Hurtado University between 2008 and 2009. Theoretical and methodological frameworks underpinning this intervention will be analysed. Drawing on its outcomes, some challenges in the field of citizenship promotion and community intervention will be pointed out.

Key words. Citizenship, community intervention, violence and fear

\section{Introducción}

Durante las últimas dos décadas la idea de ciudadanía se ha posicionado en la discusión pública como un desafío para la consolidación de las democracias en América Latina (PNUD, 2004, 2008; Braig y Huffschmid, 2009). Aunque teñida por los debates propios de países desarrollados (Kymlicka y Norman, 1994. Mouffe, 2009), la noción de ciudadanía emerge en la región 2009), la nocion de cinadania útil para contrarrestar los riesgos de populismo y la cristalización de enclaves autoritarios que abundan en nuestra historia y que agudizan la exclusión y la desigualdad (Estivill, 2003; Garretón, 2006).
La idea de ciudadanía ha estado presente ya sea explícita o implícitamente en la agenda pública chiena durante la última década, especialmente en lo que se refiere a las políticas para el control de la delincuencia, la violencia y el temor en barrios definidos como vulnerables. La seguridad ciudadana se posiciona así como un objetivo primordial de los gobiernos de turno y como tema central de discusión de muchas instituciones privadas (fundaciones, think tanks, entre otros), y por cierto, como titular obligado en los medios de comunicación masiva.

El interés público en esta temática ha sido manifestado en diversas acciones de política, entre las que 